\title{
Effect of Concomitant Extra cranial Injury in outcome of moderate and severe head injury patients admitted to a tertiary care hospital in western Nepal.
}

\author{
Pradeep Ghimire $^{1}$, Sushil Mishra ${ }^{2}$, Balgopal Karmacharya ${ }^{3}$, Nikunja Yogi ${ }^{3}$ \\ ${ }^{1}$ Consultant and Head of Department of Surgery, Manipal College of Medical Sciences, Nepal \\ ${ }^{2}$ Department of Surgery, MS Resident, Manipal College of Medical Sciences, Nepal \\ ${ }^{3}$ Consultant Neurosurgeon, Department of Neurosurgery, Manipal College of Medical Sciences, Nepal
}

\author{
Correspondence: \\ Dr. Pradeep Ghimire \\ Consultant and Head of Department of Surgery, \\ Manipal College of Medical Sciences, Nepal \\ Email: pradeep757g@gmail.com
}

\begin{abstract}
Background: Polytrauma is a term used to describe the patients those are severely injured associated with other injuries (i.e. two or more severe injuries in at least two areas of the body), less often with a multiple injury (i.e. two or more severe injuries in one body area).More than $40 \%$ of the patient of Traumatic Brain Injury (TBI) dies due to extra cranial causes. We hypothesized that extra cranial injuries with polytrauma may alter TBI outcomes and perform the study. Materials and methods: An analytical study was done with the patient of moderate to severe head injury admitted to neurosurgery Intensive Care Unit (ICU) of Manipal Teaching Hospital in between January to December 2019. The objective of the study was to assess the impact of concomitant extra cranial injury (Polytrauma) in the outcome of Moderate to severe head injury. Results: In our study it is seen that, those individuals who have presented delayed in emergency department from the time of incidence under the influence of alcohol, likewise with mean Glasgow Coma Scale (GCS) below 8.16+/-3.22 and abnormal pupils, high injury severity score (ISS), and with polytrauma have poorer outcomes. Conclusion: Concomitant extra cranial injuries, injury severity score(ISS),injuries associated under the influence of alcohol, delayed presentation in emergency after incident, GCS below 9 during presentation in ER and abnormal pupils during examinations are the strong predicting factors for the poor outcome of patient with traumatic brain injury
\end{abstract}

Key words: Glasgow Outcome Scale ,Polytrauma; Traumatic Brain Injury.

$\mathrm{P}$ olytrauma is a term used to describe the patients those are severely injured associated with other injuries (i.e. two or more severe injuries in at least two areas of the body), less often with a multiple injury (i.e. two or more severe injuries in one body area). ${ }^{1}$ The common cause of traumatic brain injury (TBI) is road traffic accident and physical assault worldwide. The causes for which patient suffer concomitant extra cranial 3 Date submitted: 02/ 01/2021

Date accepted: 13/01/2021 injuries to multiple body parts is due to high impact nature of motor vehicle accident. ${ }^{2}$ Annual incidence of traumatic brain injury is more than 50 million worldwide that remains the significant cause of injury related morbidity and mortality. ${ }^{3}$ The association of TBI and multisystem trauma is common. In literatures it has been reported that the association between TBI and polytrauma is as high as $70 \%{ }^{4}$ The impact of 
concomitant extra cranial injury on TBI remains understudied but in some literature states that there is poor outcomes of patient with polytrauma and TBI. ${ }^{5}$ Proper outcome assessment tools are critical for capturing divergence in outcomes attributable to polytrauma after TBI. More than $40 \%$ of the patient of TBI dies due to extra cranial causes. ${ }^{6}$ However, the impact of extra cranial injuries on TBI outcomes cannot be calculated with any tools. We hypothesized that extra cranial injuries with polytrauma may alter and/or confound TBI outcomes. To solve this question, we utilized data from our center to investigate the associations between concomitant extra cranial injuries and its outcomes on moderate and severe traumatic brain injury.

\section{Methods and Materials:}

An analytical study was done with the patient of moderate to severe head injury admitted to neurosurgery Intensive Care Unit (ICU) of Manipal Teaching Hospital in between January to December 2019. The objective of the study was to assess the impact of concomitant extra cranial injury (Polytrauma) in the outcome of Moderate to severe head injury. Data were collected from the Medical Record Department of the hospital on various patient and injury characteristics. Patients with Moderate to severe head injury based on admission Glasgow Coma Scale (GCS 3-12) were included in the study. Patients were divided into two groups; Group 1 having Isolated Head Injury and Group 2 consisting of TBI with Concomitant Extra cranial Injury (Polytrauma). Concomitant Extra cranial Injury was defined as any extra cranial injury with Abbreviated Injury Score (AIS) $>$ or $=3$. Data on demographic profiles, mechanism of injuries (accidents, fall, and assaults), and associated injuries, clinical features (GCS, Injury Severity Score (ISS), and AIS) were collected. Patient of both gender and age above 18 years were included in the study and those with inadequate records or who left against advice or were referred to other centers, those who died in emergency department before reaching to neurosurgical ICU were excluded from the study. Outcome was assessed in terms of Glasgow Outcome Scale (GOS) which was dichotomized for ease of statistical evaluation. GOS was assessed at the end of three months, GOS
4 and 5 were labeled as favorable and those with GOS 1, 2, 3 were labeled as unfavorable.

Various factors associated with injury were compared in between two groups using student's t test for continuous variable and chi square for categorical variables. $\mathrm{P}$ value of $<0.05$ was deemed significant for association. Statistical Package for Social Science (SPSS) software: version 21.0 was used for statistical analysis.

\section{Results:}

During the study period, total numbers of patients with moderate to severe head injury attending to emergency department of Manipal Teaching Hospital were 176. Among them 84 patients fulfilled the inclusion criteria, whereas 24 patients went against medical advice, 17 were discharged on request, 11 were referred to other center for the need of intervention from other specialty. 40 patients were excluded from the study as they did not fulfill the inclusion criteria. Among the study population, 44(52.38\%) patients had traumatic brain injury with polytrauma. The remaining 40 patients had isolated traumatic brain injury. Total patients with favorable outcomes in our study population were 39 and unfavorable outcome was 45 . The mean age of the patient that presented was $39.6+/-19.33$ years for favorable and $41.89+/-$ 20.94 for unfavorable groups with male predominance in both of the groups, however no significance was found on outcome (Table 1). Fall from height was the most common mechanism of injury accounting for $48.80 \%$ in our study populations. The average time of presentation to Emergency Room (ER) from the incident was $3.5+/-1.62$ hours in favorable groups and 6.0+/-3.9 hours in unfavorable groups which was statistically significant (Table 1). 
Ghimire $P$ et al.

\begin{tabular}{|c|c|c|c|}
\hline Variables & Favorable & Unfavorable & P-value \\
\hline $\begin{array}{cc}\text { Sex } & \\
& \text { Male } \\
& \text { Female }\end{array}$ & $\begin{array}{l}33(82.5 \%) \\
7(17.5 \%)\end{array}$ & $\begin{array}{l}35(79.5 \%) \\
9(20.5 \%)\end{array}$ & 0.811 \\
\hline Age (Mean/SD) & $39.6+/-19.33$ & $41.89+/-20.94$ & 0.606 \\
\hline $\begin{array}{c}\text { Polytrauma } \\
\text { Yes } \\
\text { No }\end{array}$ & $\begin{array}{l}12(30 \%) \\
28(70 \%)\end{array}$ & $\begin{array}{l}32(72.2 \%) \\
12(27.3 \%)\end{array}$ & $<0.01$ \\
\hline $\begin{array}{r}\text { Alcohol } \\
\text { Yes } \\
\text { No }\end{array}$ & $\begin{array}{l}9(22.5 \%) \\
31(77.5 \%)\end{array}$ & $\begin{array}{l}20(45.5 \%) \\
24(54.5 \%)\end{array}$ & 0.027 \\
\hline $\begin{array}{r}\text { Mechanism } \\
\text { Fall } \\
\text { RTA } \\
\text { Assault }\end{array}$ & $\begin{array}{l}20(50 \%) \\
16(40 \%) \\
4(10 \%)\end{array}$ & $\begin{array}{l}21(47.7 \%) \\
16(36.4 \%) \\
7(15.9 \%)\end{array}$ & 0.721 \\
\hline $\begin{array}{l}\text { Time to ER in } \\
\text { hours(Mean/SD) }\end{array}$ & $3.5+/-1.6$ & $6.0+/-3.9$ & $<0.01$ \\
\hline $\begin{array}{c}\text { Abnormal Pupils } \\
\text { Yes } \\
\text { No }\end{array}$ & $\begin{array}{l}7(17.5 \%) \\
33(82.5 \%)\end{array}$ & $\begin{array}{l}20(45.45 \% 0 \\
24(54.54 \%)\end{array}$ & 0.04 \\
\hline GCS(Mean/SD) & $10.03+/-1.88$ & $8.16+/-3.22$ & $<0.01$ \\
\hline ISS (Mean/SD) & $19.15+/-9.41$ & $31.3+/-12.54$ & 0.027 \\
\hline
\end{tabular}

In our study it is seen that, those individuals who have presented delayed in emergency department from the time of incidence under the influence of alcohol, likewise with mean GCS below 8.16+/3.22 and abnormal pupils have poorer outcomes with statistical significance (Table 1) between two groups. Injury severity score (ISS) was calculated after full assessment of the patient. In our study it was seen that, ISS was significantly higher in the patient presented with concomitant extra cranial injuries than those who have only TBI $(p=0.027)$ (Table 1).

The observed hospital mortality was $29.54 \%$ for patient with concomitant extra cranial injuries and $12.5 \%$ with isolated traumatic brain injury with $\mathrm{p}$ value of $<0.001$ (Table 2).

egneuro Volume 03, Issue 01, 2021
Table 2: Showing significant association between polytrauma and mortality.

\begin{tabular}{cccc}
\hline & $\begin{array}{c}\text { Polytrauma } \\
\text { Yes }\end{array}$ & No & P value \\
\hline Mortality & & & \\
Yes & $13(29.54 \%)$ & $5(12.5 \%)$ & $<0.001$ \\
No & $31(70.45 \%)$ & $35(87.5 \%)$ & \\
\hline
\end{tabular}

Isolated TBI was less significantly associated with unfavorable long-term outcome but TBI with polytrauma was associated with higher mortality, ISS was associated with worse long-term outcomes in patients with concomitant injuries.

\section{Discussion:}

Due to the high-impact nature of trauma-inducing factors, it is common for patients to suffer injuries to multiple body regions. ${ }^{7}$ The simultaneous traumatic injury to multiple body regions has traditionally been labeled as multitrauma or polytrauma, with the terms being used interchangeably. However, In 2014, an expert panel proposed that the term polytrauma be applied when there are two injuries that are AIS $\geq 3$ and one or more additional diagnoses (pathologic condition), that is, hypotension (systolic blood pressure $\leq 90 \mathrm{mmHg}$,), unconsciousness, acidosis (base deficit $\leq-6.0$ ), coagulopathy (partial thromboplastin time $\geq 40 \mathrm{~s}$ or international normalized ratio $\geq 1.3$ ), and age $\left(\geq 70\right.$ years) ${ }^{8}$ So ,we defined polytrauma as any extra cranial injuries with AIS $>/=3.80 .95 \%$ of the patients in our study who presented with traumatic brain injury with or without polytrauma were male with mean age of 39-41+/-19-20 years. Also it is seen that patients with TBI and polytrauma have consumed alcohol $(34.09 \%)$ than the groups without polytrauma $(77.5 \%)$ which could be the precipitating factor for the mechanism of injury. Various etiology and mechanisms of polytrauma has been discussed in different literature among them motor vehicle accident has been kept in rank one, however our study showed fall injury was the most common mechanism of injury $(48.80 \%)$ followed by road traffic accident (38.09\%) and physical assault (13.09\%). The incidence of fall are 
higher in our population due to the geographical nature of our country mostly hilly and mountain territory. The patients of TBI with or without polytrauma who presented late in ER have slightly high poor outcomes, and the mean time to present in emergency department was 3.5+/-1.6-+/- 6.0+/3.9 hours in favorable and unfavorable groups respectively. The delayed presentation in our population is due to lack of easy patient carrying vehicles and ambulance in our country. Those who presented with TBI with polytrauma showed slightly high level of blood glucose (157.64+/58.27) than those without polytrauma (144.5+/53.22), this can be explained as the more release of the stress hormone in response to polytrauma. Similarly from our study we concluded that outcomes of the patient with TBI can be influenced by polytrauma $(p<0.001)$ and Injury severity score $(p=0.027)$ significantly that can be in the form severe disability or vegetative state or even death of the patient $(\mathrm{p}<0.01)$.The different types of concomitant extra cranial injuries that affects the outcome on traumatic brain injury is enlisted in table 3. It is seen that patients who presented with TBI and polytrauma has long ICU stay with different surgical procedures and interventions that affects the outcomes as in our study populations. The GOS of 1, 2, 3, was regarded as unfavorable where as those of score 4,5 as favorable. The difference of both group was statistically significant suggesting higher unfavorable outcome in the patient of TBI with polytrauma $(<0.01)$.Many literatures can be taken as a references or supporting articles for our study like, a study done by Be Kim Leong et al. showed that In TBI survivors, extra cranial concomitant injuries AIS grade $\geq 3$ influenced the long-term functional outcome at 18 months, causing moderate and severe disabilities. ${ }^{9}$ Likewise a study done by John $\mathrm{k}$ yue et al. concluded that TBI patients with polytrauma are at greater risk for 3-and 6-month disability than patients with isolated $\mathrm{TBI}^{10}$ Similarly a study done by Johannes leitgeb et al. showed that concomitant injuries were found in nearly half of the patients. Hospital mortality was $2.8 \%$ higher, and the rate of unfavorable outcome was $8.6 \%$ higher in patients with isolated TBI. Concomitant injuries were associated with significantly higher mortality in the few patients with AIS $=2$. Concomitant injuries were also associated with longer duration of ventilation, and longer ICU and hospital stay. ${ }^{11}$ Another study done by Mujan sun et.al. Summarize that concomitant extra cranial injuries are capable of modifying the outcomes and pathobiology of traumatic brain injury.

Table 2: TBI associated with other extra cranial concomitant injuries.

\begin{tabular}{|c|c|c|}
\hline S.N & Concomitant Extra cranial injuries & Incidence \\
\hline \multirow[t]{3}{*}{1.} & Blunt chest trauma & \\
\hline & Pneumothorax and hemothroax & $16(36.36 \%)$ \\
\hline & Rib fractures & $14(31.81 \%)$ \\
\hline 2. & $\begin{array}{l}\text { Blunt abdominal and solid organ } \\
\text { injuries (liver,spleen,kidney) }\end{array}$ & $10(22.72 \%)$ \\
\hline \multirow[t]{5}{*}{3.} & Skeletal injury & \\
\hline & Pelvic fractures & $6 \quad(13.63 \%)$ \\
\hline & Long bone fractures including & $24(54.55 \%)$ \\
\hline & clavicles & $7(11.36 \%)$ \\
\hline & Maxilla and facial bone fracture & \\
\hline 4. & Nasal fractures and epistaxis & $14(31.81 \%)$ \\
\hline 5. & Spinal injuries & $5(9.09 \%)$ \\
\hline 6. & Others & $7 \quad(15.90 \%)$ \\
\hline
\end{tabular}

\section{Conclusion:}

Concomitant extra cranial injuries (polytrauma),injury severity score(ISS),injuries associated after consumption of alcohol in subconscious mind, delayed presentation in emergency after incident, GCS below 9 during presentation in ER and abnormal pupils during examinations are the strong predicting factors for the outcome of patient with traumatic brain injury which was statistically significant in our study.

\section{References:}

1. Lefering R, Bouillon LR, Neugebauer EA. Head injury and outcome: what influence do concomitant injuries have? J Trauma 2008; 65:1036-43.

2. McDonald et al. Journal of Neuroinflammation (2016) 13:90 DOI 10.1186/s12974-016-0555-1(Stuart J. McDonald1*, Mujun Sun2, Denes V. Agoston3 and Sandy R. Shultz2*).

egneuro, Volume 03, Issue 01, 2021 
3. Taylor, C.A., Bell, J.M., Breiding, M.J., and Xu, L. (2017). Traumatic brain injury-related emergency department visits, hospitalizations, and deaths - United States, 2007 and 2013. MMWR Surveill. Summ. 66, 1-16.

4. Xydakis, M.S, Ling,G.S.F, Mulligan, L.P. Olsen, C.H, and Dorlac, W.C. (2012). Epidemiologic aspects of traumatic brain injury in acute combat casualties at a major military medical center: a cohort study. Ann. Neurol. 72, 673-681.

5. Gross, T., Schu“ epp, M., Attenberger, C., Pargger, H., and Amsler, F. (2012). Outcome in polytraumatized patients with and without brain injury. Acta Anaesthesiol. Scand. 56, 1163-1174.

6. Kemp CD, Johnson JC, Riordan WP, Cotton BA (2008) How we die: the impact of nonneurologic organ dysfunction after severe traumatic brain injury. Am Surg 74(9):866-872.

7. MacGregor AJ, Mayo JA, Dougherty AL, Girard PJ, Galarneau MR. Injuries sustained in noncombat motor vehicle accidents during Operation Iraqi Freedom. Injury. 2012; 43:1551-5.

8. Pape HC, Lefering R, Butcher N, Peitzman A, Leenen L, Marzi I, et al. The definition of polytrauma revisited: an international consensus process and proposal of the new 'Berlin definition'. J Trauma Acute Care Surg. 2014; 77:780-6.

9. Butcher N, Balogh ZJ. The definition of polytrauma: the need for international consensus. Injury. 2009; 40 Suppl 4:S12-22.

10. Yue J K, Gabriela G. Satris, Cecilia L. Ore D, Huie R, et.al. Neurotrauma Reports Volume 1.1, 2020 DOI: 10.1089/neur.2020.0004.

11. Leitgeb J, Mauritz W, Brazinova A, Majdan M, Wilbacher I et.al..Arch OrthopTrauma Surg (2013) 133:659-668 DOI 10.1007/s00402-013-1710-0. 